\title{
Relative impact of parrotfish grazing scars on massive Porites corals at Lizard Island, Great Barrier Reef
}

\author{
R. M. Bonaldo ${ }^{1,2, *}$, J. P. Krajewski ${ }^{3,4}$, D. R. Bellwood ${ }^{2}$ \\ ${ }^{1}$ School of Biology, Georgia Institute of Technology, Atlanta, Georgia 30332, USA \\ ${ }^{2}$ Australian Research Council Centre of Excellence for Coral Reef Studies and School of Marine and Tropical Biology, \\ James Cook University, Townsville, Queensland 4811, Australia \\ ${ }^{3}$ Laboratorio de Biogeografia e Macroecologia Marinha, Departamento de Ecologia e Zoologia, \\ Universidade Federal de Santa Catarina, Florianópolis 88010-970, Brazil \\ ${ }^{4}$ Departamento de Zoologia, Instituto de Biologia, Universidade Estadual de Campinas, Campinas SP 13083-862, Brazil
}

\begin{abstract}
Scraping and excavating parrotfishes are well known for their marked differences in jaw morphology and feeding behaviour. Despite the importance of parrotfishes to reef systems and the well-known differences within the group, few studies have compared the functional importance of scraping versus excavating parrotfishes in shaping coral reef benthic communities. We compared the abundance, depth and dynamics of scraping and excavating parrotfish grazing scars on massive Porites spp. colonies along a reef gradient at Lizard Island, northern Great Barrier Reef. Scraping grazing scars were more abundant at most study sites than excavating scars. Excavating grazing scars were relatively rare but exposed more coral skeleton than scraping scars. Approximately $70 \%$ of excavating scars had some degree of filamentous algal growth in the scar compared with just $5 \%$ of scraping scars. Scraping grazing scars on massive Porites spp. completely disappeared after 2 mo whereas excavating grazing scars remained almost unchanged over this period. Groups of excavating scars were more tightly clustered, exposed more coral skeleton and presented higher algal cover than grouped scraping scars. The deep, long-lasting excavating scars probably provide more suitable sites for the settlement of benthic algae and other invasive taxa on coral colonies. In contrast, the abundant and frequent grazing scars of scraping parrotfish may represent a more constant drain on energy supplies for coral colonies. These results highlight the differences between parrotfishes with distinct feeding modes and indicate that they differently impact not only algal communities but also coral colonies.
\end{abstract}

KEY WORDS: Coral reef · Scarinae (Labridae) · Scraping parrotfish • Excavating parrotfish • Bite marks $\cdot$ Corallivory $\cdot$ Reef zone $\cdot$ Australia

\section{INTRODUCTION}

Parrotfishes have been intensively studied during the past 2 decades because of their recognized importance to coral reef resilience (e.g. Bellwood et al. 2004, Mumby et al. 2006, Paddack et al. 2006, Hughes et al. 2007). These fishes have been associated with a number of crucial roles on coral reefs, ranging from the control of algal growth to bioerosion and coral predation (e.g. Bellwood et al. 2003, Sánchez et al. 2004, Rot- jan \& Lewis 2005, Mumby et al. 2006, Paddack et al. 2006, Alwany et al. 2009, Mumby 2009). In addition to the general importance of the parrotfish clade on tropical reefs, a number of studies have highlighted the impact of individual parrotfish groups, species and even individual size classes in shaping the nature and intensity of their ecosystem roles (e.g. Bruckner \& Bruckner 1998, Bellwood et al. 2003, Bonaldo \& Bellwood 2008, 2009, Francini Filho et al. 2008, Alwany et al. 2009). 
The diversity of feeding modes within the parrotfish clade has been considered one of the main factors contributing to the diversity of functional roles within the group (e.g. Bellwood \& Choat 1990, Fox \& Bellwood 2007, Francini-Filho et al. 2008, Alwany et al. 2009, Bonaldo \& Bellwood 2009). In general, parrotfish species on coral reefs may be classified into 2 main functional groups: scrapers and excavators (sensu Bellwood \& Choat 1990). These groups differ markedly in their feeding morphology and behaviour. Scraping species possess a less robust feeding apparatus, take smaller bites from the substratum and have higher feeding rates than excavating parrotfishes. Scrapers and excavators also leave different bite marks, usually termed grazing scars, on the substratum when feeding. Excavating species usually leave larger and deeper grazing scars when feeding, removing not only the superficial layer of the substratum but also pieces of consolidated reef matrix (Bellwood \& Choat 1990, Bruggemann et al. 1994b, Bonaldo \& Bellwood 2009). As a consequence, these species have a distinctly different impact on the development of algal communities on the substratum on which they feed (Bonaldo \& Bellwood 2009). Although some large scrapers may leave deeper scars, on the Great Barrier Reef (GBR), Australia, the 16 Scarus species and Hipposcarus longiceps are all considered scrapers, whereas Bolbometopon muricatum, Cetoscarus bicolour and 5 Chlorurus species are all classified as excavators (Bellwood \& Choat 1990, Bellwood et al. 2003). This division reflects the marked differences in the morphology of the jaws in the 2 functional groups (Bellwood 1994).

Despite the importance of parrotfishes to reef systems and the well-known differences within the group, few studies have compared the functional importance of scraping versus excavating species. Furthermore, although parrotfishes have been widely acknowledged to be a significant factor determining the distribution and abundance of coral colonies on coral reefs (e.g. Littler et al. 1989, Hixon 1997, Rotjan \& Lewis 2006, Bonaldo \& Bellwood 2011), little is known about the relative contribution of scraping and excavating species to this process. Previous studies have found that scraping and excavating parrotfish species may exhibit profound differences in the way they affect algal communities on coral reefs (e.g. Bonaldo \& Bellwood 2009) and it is possible that these differences may be extended to coral colonies as well.

To examine the relative effects of these 2 major parrotfish groups on reef corals, and to evaluate their role as coral predators, we assessed the abundance, depth and dynamics of parrotfish grazing scars on reefs in the Lizard Island group, northern GBR. Specifically, we compared scraping and excavating parrotfish grazing scars on massive Porites spp. colonies by answering the following 4 questions: (1) How abundant are scraping and excavating grazing scars in different reef zones? (2) How much coral skeleton is exposed by these grazing scars? (3) What is the small-scale spatial distribution of these grazing scars? (4) How long do these grazing scars persist?

\section{MATERIALS AND METHODS}

Study area. This study was conducted between September 2008 and January 2009 in the Lizard Island region, a mid-shelf reef in the northern section of the GBR. Specifically, we examined 2 sites between South and Palfrey Islands (14 $\left.41^{\prime} 5^{\prime \prime} \mathrm{S}, 145^{\circ} 26^{\prime} 55^{\prime \prime} \mathrm{E}\right)$. Within each study site, 4 reef zones were selected: backreef (5-8 $\mathrm{m}$ deep), flat $(0.5-1 \mathrm{~m})$, crest $(0.7-2 \mathrm{~m})$ and slope $(7-10 \mathrm{~m})$ (Fig. 1). These 4 reef zones were selected as they have been previously shown to markedly differ in terms of parrotfish assemblage,

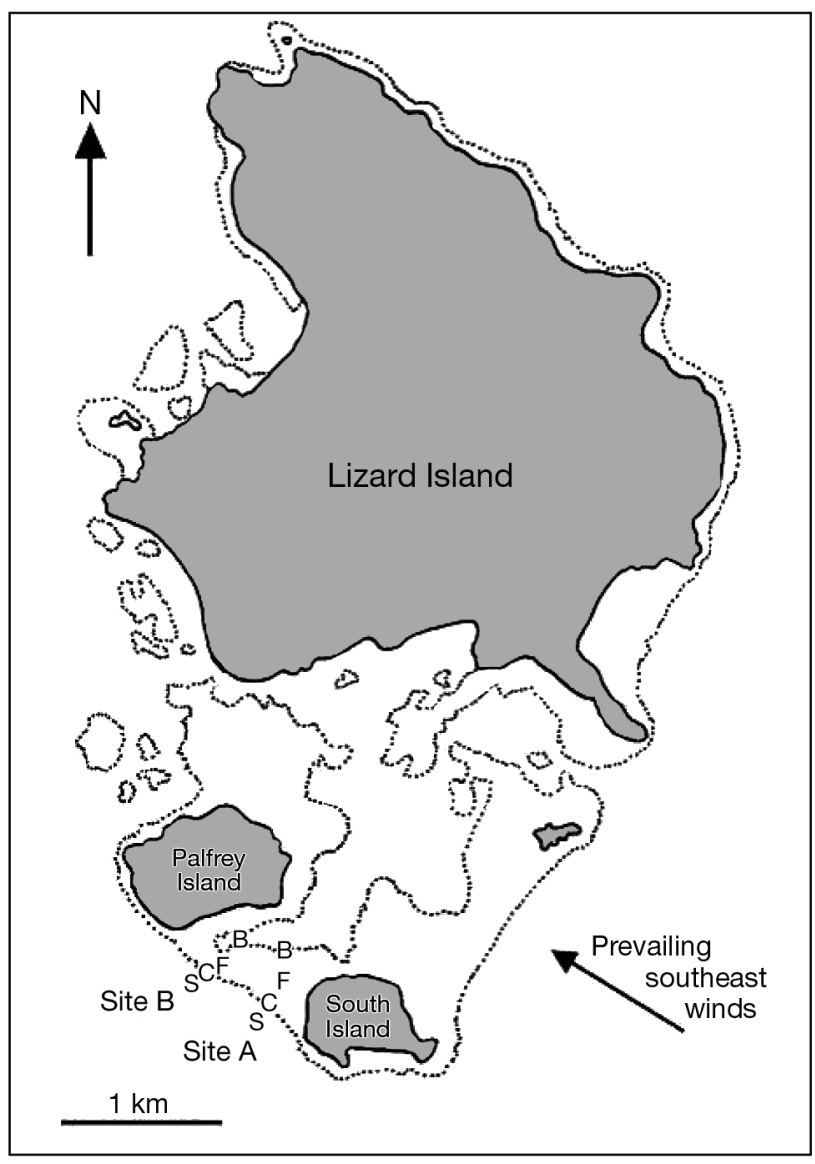

Fig. 1. Location of study sites at Lizard Island, Great Barrier Reef. Reef zones at each study site are classified as backreef (B), crest (C), flat (F) and slope (S) 
benthic composition and intensity of corallivory (Bonaldo \& Bellwood 2011). The inclusion of all of these zones therefore provides a more reliable picture of corallivory in the selected area. During the study, water visibility ranged between 10 and $15 \mathrm{~m}$ and temperature was 27 to $29^{\circ} \mathrm{C}$.

Relative abundance of scraping and excavating grazing scars. The presence of the distinctive grazing scars made by parrotfishes on live coral was used as an indicator of parrotfish feeding on corals (following Littler et al. 1989, Rotjan \& Lewis 2005, Bonaldo \& Bellwood 2011). However, before starting our data collection we followed approximately 30 parrotfish individuals in September 2008 to observe the shape of their grazing scars on coral colonies in the study area (see Bonaldo \& Bellwood 2011). On the basis of these observations, only very clear parrotfish grazing scars were used, as these present the typical bite marks of parrotfishes and can be classified as a scraping or excavating (Fig. 2). We have also observed fresh bite marks of pufferfishes in the field and compared these with bite marks of scraping parrotfishes to make sure we would be able to distinguish them. At this site, they more closely resemble scraping than excavating scars, but parrotfish grazing scars are characterized by 2 larger narrow parallel scrapes (caused by the dentary) and 2 shorter marks (left by the upper jaw [premaxilla]). This methodology results in a conserva- tive estimate of coral predation by parrotfishes and avoids the confusion with grazing scars left by other organisms, such as monacanthids, tetradontids and labrids (cf. Jayewardene \& Birkeland 2006, Cole et al. 2008, Jayewardene et al. 2009). However, non-scarid or unconfirmed scars represented less than $1 \%$ of all scars located.

Observations were restricted to grazing scars on massive Porites spp. This coral group was chosen as it is consistently present in all 4 reef zones, exhibits clearly distinguishable grazing scars and exhibits the highest abundance of grazing scars at the study sites (Bonaldo \& Bellwood 2011). Because of the difficulty in distinguishing massive Porites species on the GBR, colonies were classified as 'massive Porites spp.'.

The relative abundance of scraping versus excavating and solitary versus grouped parrotfish bite marks on coral was determined by surveying seven $20 \mathrm{~m}$ transects within each study location. This procedure was undertaken in September and December 2008. In each transect, high-definition photographs of the bottom were taken every meter at a standardized distance of $1 \mathrm{~m}$ from the reef substratum. The total area of each photograph was $480 \mathrm{~cm}^{2}$, resulting in a sampled area of approximately $10.1 \mathrm{~m}^{2}$ per transect. Subsequently, photographs in which massive Porites spp. colonies were present were analysed to quantify any parrotfish bite marks. When present, bite marks were counted
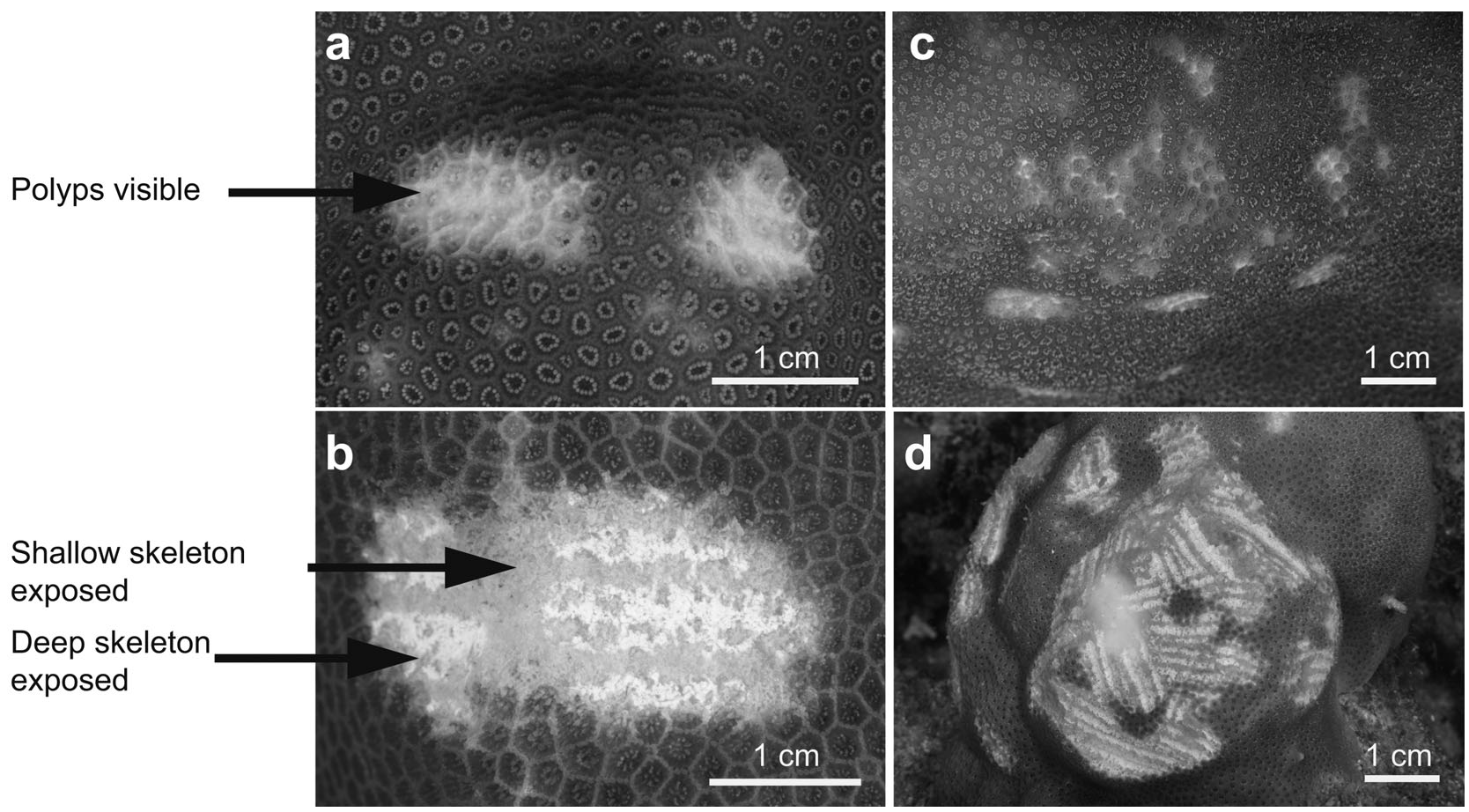

Fig. 2. Individual grazing scars of solitary (a) scraping and (b) excavating parrotfishes and groups of grazing scars of (c) scraping and (d) excavating parrotfishes. Arrows indicate the regions of grazing scars in the 3 depth categories considered in the present study (polyps visible, shallow skeleton exposed and deep skeleton exposed) 
and classified into type (scraping or excavating) and number (solitary or grouped). Scraping and excavating parrotfish grazing scars have a distinct shape and size (Fox \& Bellwood 2007, Bonaldo \& Bellwood 2009). Scraping parrotfish grazing scars are usually elongated and do not present the multiple grooves typical of excavating grazing scars (Fig. 2). Groups of grazing scars were defined as 3 or more grazing scars on the same massive Porites colony with a maximum distance of $0.5 \mathrm{~mm}$ between scars. Absolute values for the total number of parrotfish grazing scars and individuals in the study zones and sites have been examined previously (Bonaldo \& Bellwood 2011) and, for this reason, the present study focuses on the relative proportion of scraping and excavating forms.

Relative abundance of scraping and excavating parrotfish individuals. Parrotfish abundance was assessed in each study site to examine the relationship between the relative abundance of scraping and excavating parrotfish individuals and grazing scars. Nine $50 \times 2 \mathrm{~m}$ tape transects were surveyed within each of the 4 zones at the 2 sites during October and December 2008 ( $\mathrm{n}=96$ ). To minimize diver effects, censuses were undertaken while deploying the transect tape. Fish counts were based on all individuals over $10 \mathrm{~cm}$ total length, which were classified into functional group (scraping and excavating). All visual censuses were conducted within $2 \mathrm{~h}$ of the high tide in the morning to minimize any effects of tide or time of day.

Coral skeleton exposure and algal cover of scraping and excavating grazing scars. As excavating grazing scars of parrotfishes were rare at the study sites, larger transects were used to examine the nature of parrotfish grazing scars. Two $5 \times 500 \mathrm{~m}$ transects were examined in the reef crest/slope region in January 2010. All complete parrotfish grazing scars on massive Porites spp. (i.e. those scars presenting the typical marks of 2 parrotfish jaws; Fig. 2) in the transects were photographed with a scale. Each photograph was taken in 2 different modes: macro and super macro. Macro mode was used to obtain a better visualization of the scar size and shape whereas super macro was used to quantify the presence of algae on the scars. For both modes, photographs were taken with a housed Canon EOS 40D 10 megapixel camera using a $100 \mathrm{~mm}$ macro lens with a 1.4 teleconverter and manual focus. A shutter speed of $1 / 200 \mathrm{~s}$ and 2 Sea and Sea YS110 strobes on full power were used to minimize the entrance of natural light and ensure uniform light conditions for all photographs. For macro and super macro photographs, distances of 40 and $10 \mathrm{~cm}$, respectively, were used between the camera and the grazing scar.

Grazing scars were analysed using Image Tool software (version for Windows 3.0). Each grazing scar was classified into type (scraping or excavating), age (fresh, i.e. still presenting ripped pieces of coral around on its margins, and older) and association (solitary and grouped) categories. Only one grazing scar or grazing scar group per massive Porites spp. colony was considered for the analyses to maximize independence of samples.

For each photograph, measurements were taken of the scar area using Image Tool. Also, each scar was classified into 3 categories of scar depth: (1) polyps visible, (2) shallow coral skeleton exposed (coral tissue with pigments visible) and (3) deep coral skeleton exposed (no coral tissue pigment visible) (Fig. 2). Photographs were also analysed to verify whether grazing scars had any algal cover. When present, algal cover was quantified and visually classified into the following area-covered categories: $<5 \%, 5-50 \%$ and 50-100\%. This procedure was checked for accuracy using Image Tool.

For photographs of grouped grazing scars, in addition to depth and algal cover, measurements were taken of the total group area (i.e. the minimum complex polygon encompassing grazing scars in the group) and total grazed area (i.e. the grazed region of the group only, not including the gaps of coral tissue between scars). These measurements were used to calculate the density of grazing scars in the group and relative grazed area of the group.

Longevity of individual parrotfish grazing scars. The duration of parrotfish grazing scars on massive Porites spp. colonies was evaluated by surveying 160 individual colonies. These colonies were haphazardly chosen and photographed over 14 consecutive days during October 2008 (2240 photographs). To ensure that the same colonies were photographed every day, identification tags were placed approximately $50 \mathrm{~cm}$ from each colony. Photographs were always taken of the same region of each colony, which was delimited using a $22 \times 22 \mathrm{~cm}$ plastic frame. For each colony, the external corners where the plastic frame was placed were marked with black pencil to allow divers to find the exact area of each colony to be photographed during the entire period. Photographs were examined regarding the number of parrotfish grazing scars and the grazed area of each colony over the $14 \mathrm{~d}$ period. From these 160 colonies, a total of 33 and 10 presented new grazing scars of scraping and excavating parrotfishes, respectively, after $14 \mathrm{~d}$ following the initial observation. New grazing scars were recorded, identified and measured. Only one grazing scar per massive Porites colony was considered to maximize sample independence. Photographs of all fresh grazing scars were measured using Image Tool. The locations of all massive Porites colonies that displayed new parrotfish grazing scars during the $14 \mathrm{~d}$ observation period in 
October 2008 were noted. In December 2008, these same colonies were re-photographed, approximately 60 d later, to evaluate whether grazing scars were still present. Photographs were analysed using software Image Tool to compare the area of grazing scars over the $60 \mathrm{~d}$ period.

Statistical analyses. The relative abundance of scraping and excavating parrotfish grazing scars was compared with a 3-way ANOVA, in which month, study site and reef zones were fixed factors. The same test was used to compare the relative abundance of scraping and excavating parrotfish individuals. Data were arcsine-transformed prior to analyses. The relationship between the relative abundance of parrotfish individuals and grazing scars was examined using a Pearson correlation matrix.

The degree of coral skeleton exposure by parrotfish grazing scars were compared using 2 G-tests for a $3 \times 2$ contingency table: (1) fresh versus older scraping parrotfish grazing scars and (2) fresh versus older excavating parrotfish grazing scars. For all G-tests, the 3 coral depth categories (polyp visible, shallow skeleton exposure and deep skeleton exposure) were used as rows. For the analyses of scraping grazing scars, the 2 deeper categories (shallow and deep skeleton exposure) were combined because of small sample sizes.

The relative abundance of grouped grazing scars across the 4 studied reef zones was compared with a 3-way ANOVA with month, sites and reef zones as fixed factors. Groups of scraping and excavating parrotfish grazing scars were compared with Student's $t$-tests for the following variables: (1) number of grazing scars in the group (number of scars per group), (2) relative area grazed (area of scars per group area) and (3) relative algal cover of the scars.

Relative algal cover on individual and grouped grazing scars was compared with Mann-Whitney $U$-tests, which were done separately for scraping and excavating grazing scars. The same test was used to compare the extent of change in the initial area of scraping and excavating parrotfish grazing scars 2 mo after their appearance on massive Porites spp. colonies.

Data were examined for normality and homogeneity of variance before all tests with residual analyses. When significant differences were found in ANOVAs, post hoc tests (Tukey's) were used to verify the specific sources of variation.

\section{RESULTS}

The relative abundance of excavating and scraping parrotfish grazing scars differed among the 4 studied reef zones. Reef flat, crest and slope presented higher abundance of scraping than of excavating grazing scars, whereas the backreef had the opposite pattern $\left(F_{3}=32.36, \mathrm{p}<0.001 ;\right.$ Fig. 3a). No month $\left(F_{1}=0.31, \mathrm{p}=\right.$ $0.58)$ or site $\left(F_{1}=1.88, \mathrm{p}<0.17\right)$ effects were detected and all factor interactions were non-significant $(\mathrm{p} \geq$ 0.10 for all possible interactions).

The relative abundance of scraping and excavating individuals mirrored the distribution of their respective grazing scars across the reef gradient. Backreef was the only zone that presented a similar number of scraping and excavating grazing scars; in the other 3 study zones scraping scars significantly outnumbered their excavating counterparts $\left(F_{3}=11.70, \mathrm{p}<0.001\right.$; Fig. $\left.3 \mathrm{~b}\right)$. No month and site effects were detected $(\mathrm{p} \geq 0.14$ for all possible comparisons). The relative abundance of scraping and excavating parrotfish individuals was positively related to the abundance of their respective grazing scars (Pearson correlation coefficient $r=0.69$, $\mathrm{p}=0.001$; Fig. 3).

Scraping and excavating parrotfish grazing scars differed in the degree of coral skeleton exposure on massive Porites spp. colonies $\left(G_{2}=30.26\right.$, p $<0.001$; Fig. $4 \mathrm{a}, \mathrm{b})$. In general, grazing scars of scraping parrot-
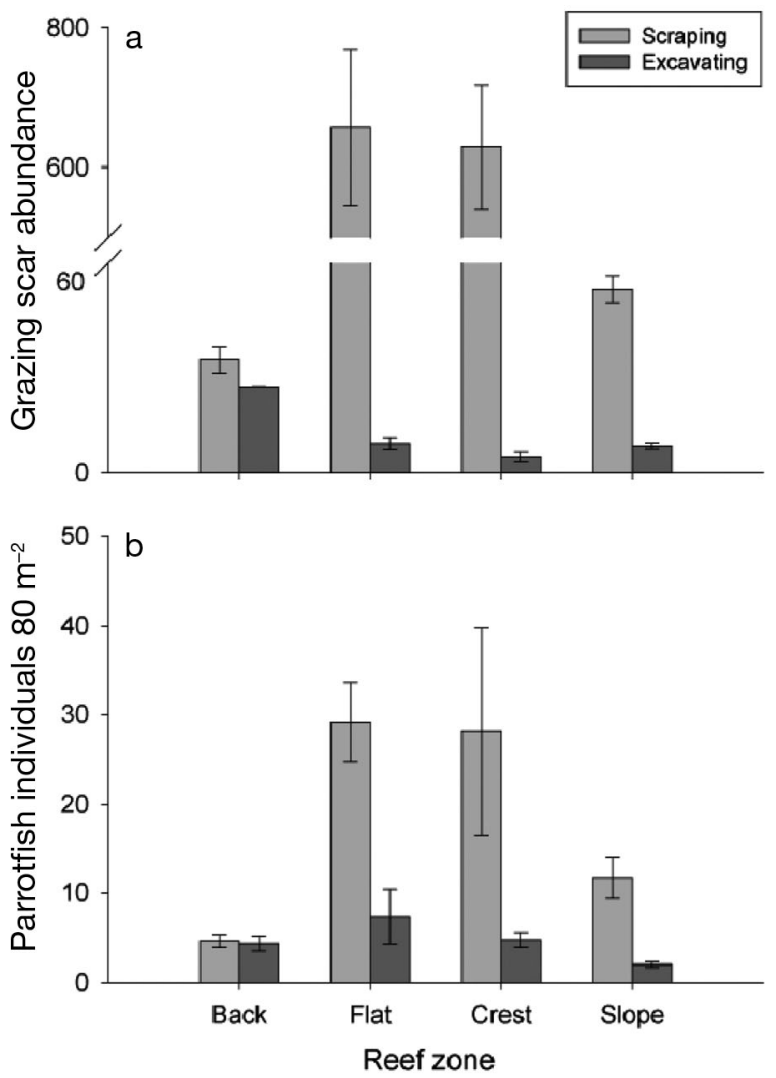

Fig. 3. Abundance (mean $\pm \mathrm{SE}$ ) of (a) scraping and excavating parrotfish grazing scars on the surface of massive Porites spp. $\left(\mathrm{m}^{-2}\right.$ of coral surface) across a reef gradient and (b) parrotfish individuals $80 \mathrm{~m}^{-2}$ of reef on Lizard Island, Great Barrier Reef 
fish had coral polyps still visible whereas excavating grazing scars usually exposed the coral skeleton, with few or no coral polyps visible. Fresh and older grazing scars also differed on their depth, as new scars were usually deeper, exposing more coral skeleton. These differences were significant for both excavating $\left(G_{2}=\right.$ 22.29, $\mathrm{p}<0.001)$ and scraping scars $\left(G_{2}=10.03, \mathrm{p}<\right.$ $0.007)$.

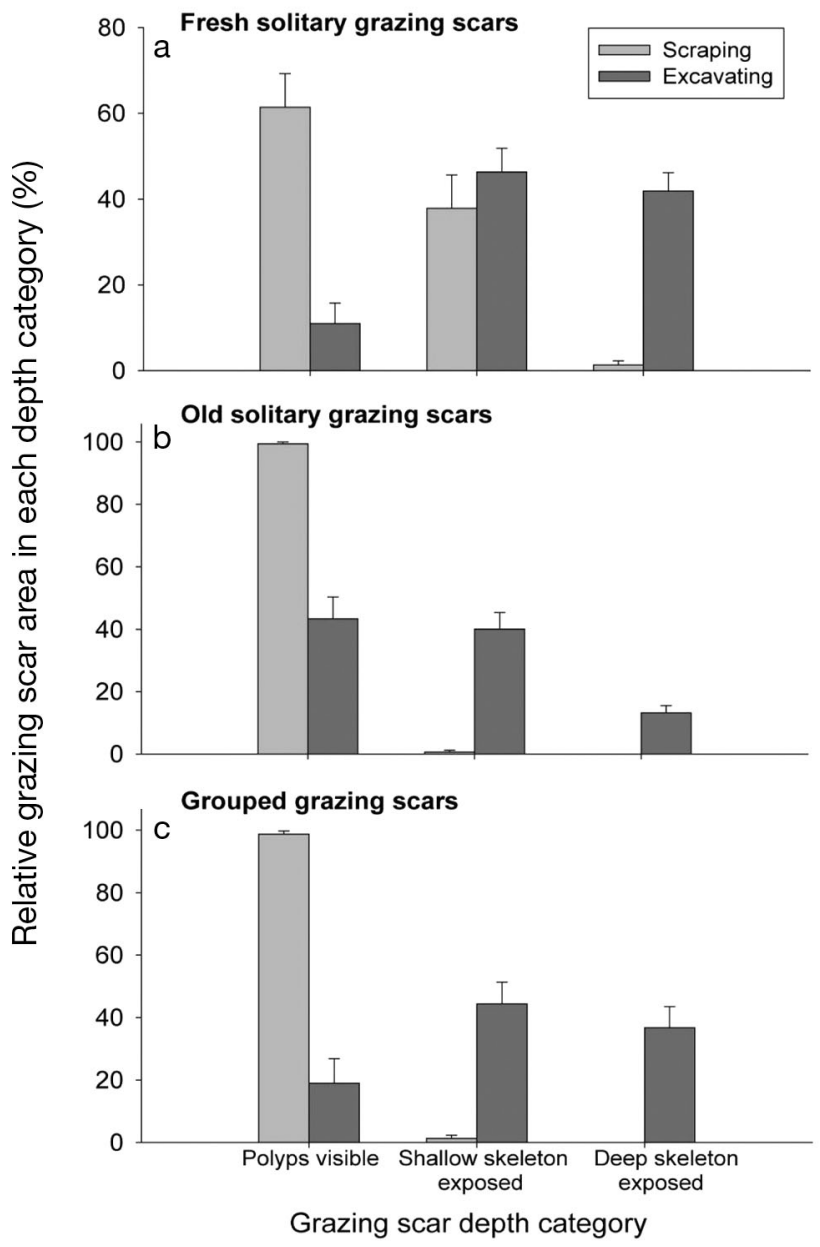

Fig. 4. Relative area (mean \pm SE) of (a) fresh, (b) old and (c) grouped scraping and excavating parrotfish grazing scars on massive Porites spp. in the 3 scar depth categories considered in the present study (polyps visible, shallow skeleton exposed and deep skeleton exposed)
Reflecting grazing scar depth, algal cover was higher on excavating than on scraping grazing scars. For scraping grazing scars, both fresh and older scraping grazing scars had very low algal cover, not reaching $1 \%$ of total scar area. For excavating grazing scars, although a higher number of older grazing scars presented more than $50 \%$ of algal cover, differences in the algal content between fresh and older scars were not significant $\left(G_{3}=4.10, \mathrm{p}=0.25\right.$; Fig. 5).

The reef crest and flat presented relatively more grouped scars than backreef and slope $\left(F_{3}=9.19\right.$, p < $0.001)$, with no significant month $\left(F_{1}=2.47, \mathrm{p}=0.12\right)$ or site $\left(F_{1}=0.14, \mathrm{p}=0.71\right)$ effects nor factor interactions ( $p>0.12$ for all possible interactions). In the backreef

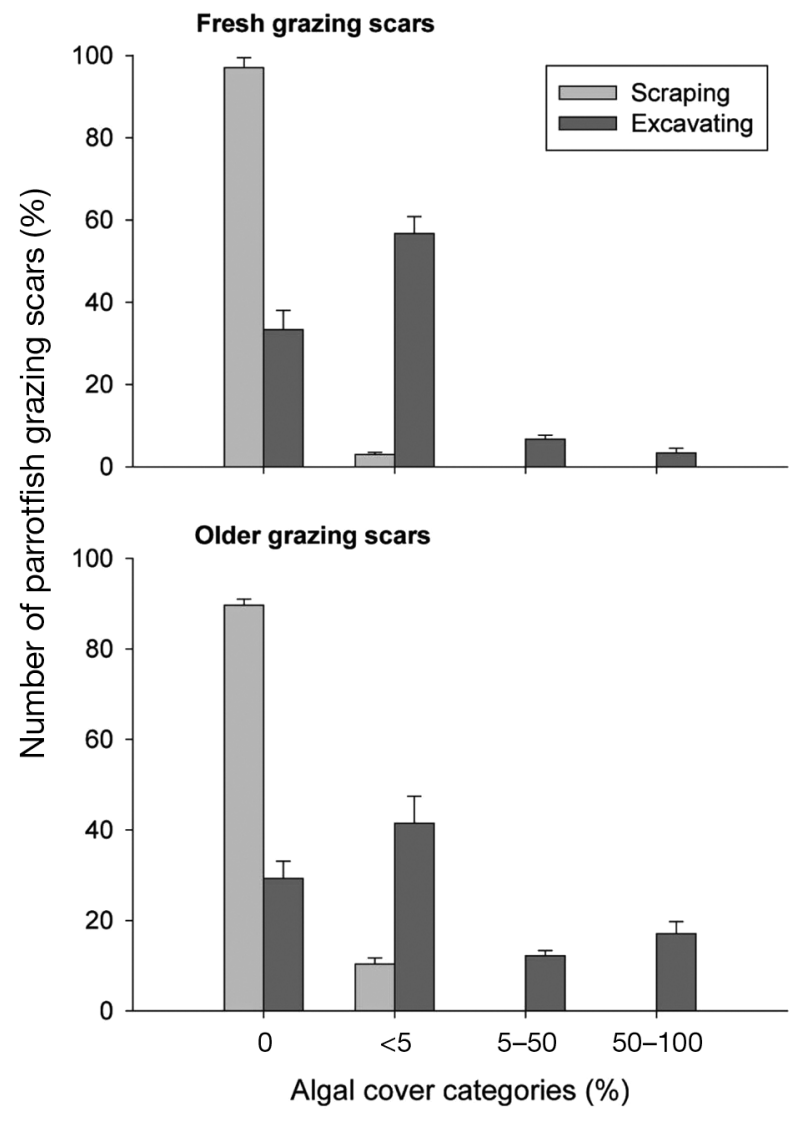

Fig. 5. Algal cover (mean \pm SE) on fresh and older grazing scars of scraping and excavating parrotfishes

Table 1. Comparison of groups of scraping and excavating parrotfish grazing scars on massive Porites spp. at Lizard Island. Values are expressed as means \pm SE. Significant $\mathrm{p}$-values are highlighted in bold

\begin{tabular}{|c|c|c|c|c|}
\hline & Scraping $(\mathrm{n}=33)$ & Excavating $(\mathrm{n}=16)$ & $t$ & $\mathrm{p}$ \\
\hline Number of grazing scars (no. group ${ }^{-1}$ ) & $15.8 \pm 3.6$ & $12.2 \pm 2.3$ & -0.38 & 0.71 \\
\hline Grazed area per group area (\%) & $69.7 \pm 17.3$ & $95.5 \pm 2.4$ & 2.97 & 0.008 \\
\hline Groups with algae (\%) & 21.2 & 87.5 & & \\
\hline$\%$ algal content in the scars in the group & $2.5 \pm 1.7$ & $21.2 \pm 8.2$ & 2.93 & 0.009 \\
\hline
\end{tabular}




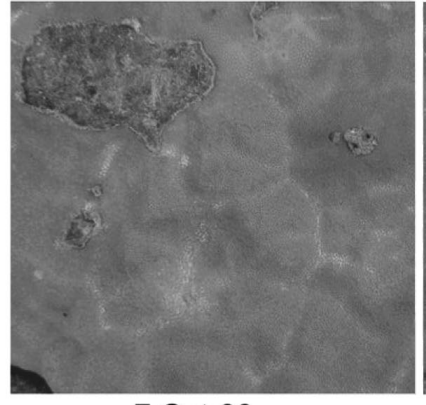

7 Oct 08

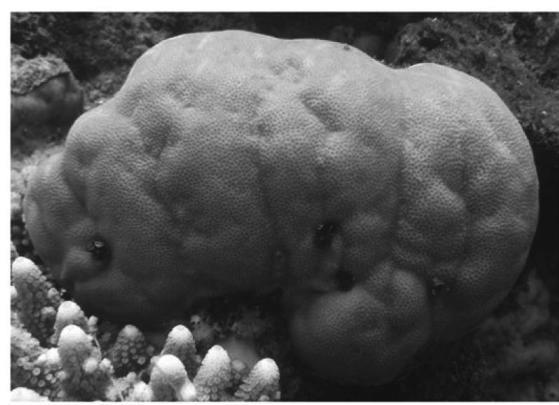

7 Oct 08

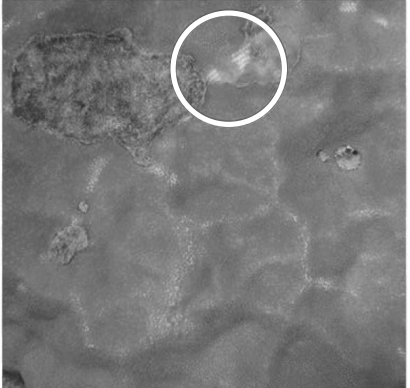

14 Oct 08

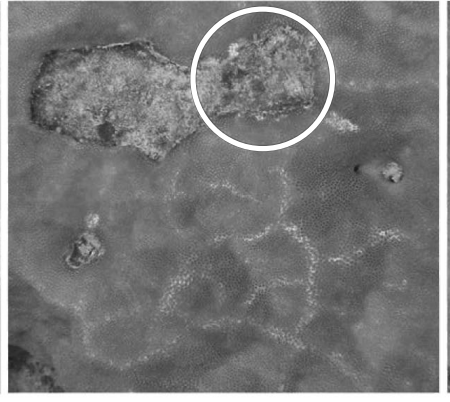

$23 \mathrm{Dec} 08$

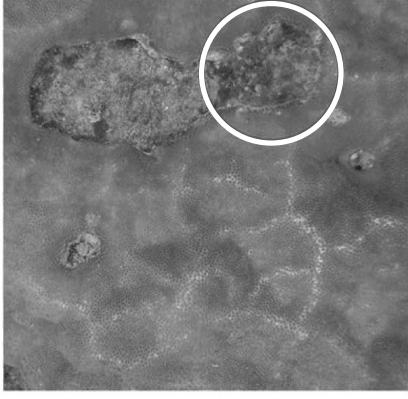

16 Jan 09

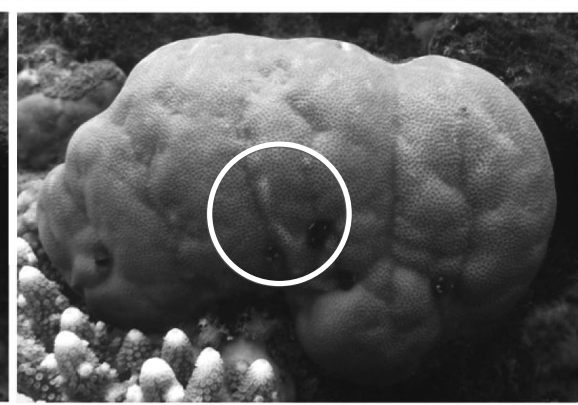

14 Oct 08

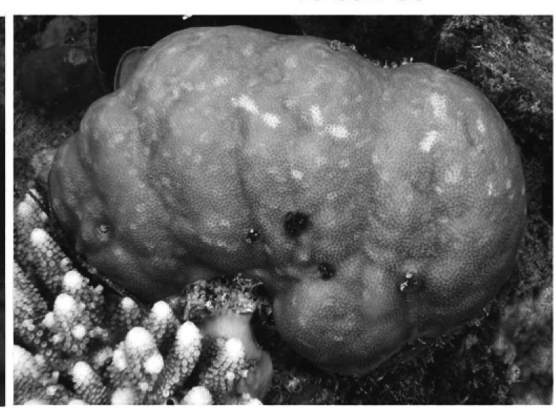

23 Dec 08

Fig. 6. Two examples of massive Porites spp. with fresh excavating (top) and scraping (bottom) parrotfish grazing scars in October 2008. Fresh grazing scars are highlighted by circles. Notice that the scraping grazing scar completely disappeared by December 2008 whereas the area with the excavating scar was completely covered by algae

and slope, $26.07 \pm 6.52 \%$ (mean $\pm \mathrm{SE}$ ) and $22.81 \pm$ $4.89 \%$, respectively, of the grazing scars on massive Porites spp. were grouped, compared with $51.78 \pm$ $8.94 \%$ in the flat and $69.50 \pm 6.40 \%$ in the reef crest. All grazing scar groups presented only one type of parrotfish grazing scar. Relative algal cover was significantly higher on grouped than on individual scars for both scraping ( $\left.U_{1}=666, \mathrm{p}=0.019\right)$ and excavating scars $\left(U_{1}=370, \mathrm{p}=0.002\right)$ (Table 1$)$.

Grazing scars of scraping and excavating parrotfishes also differed in their duration on massive Porites spp. colonies. After 2 mo following the scar appearance, only 3 out of 33 scraping grazing scars were still visible. In contrast, all 10 excavating grazing scars were still visible after 2 mo following their first appearance and 3 had increased in area (Fig. 6). Differences in the area reduction rate between the 2 types of grazing scars was significant $\left(U_{1}=328, \mathrm{p}<0.001\right)$, as scraping scars had a reduction of $98.27 \pm 1.32 \%$ of their initial area in 2 mo compared with just $10.09 \pm 17.39 \%$ for excavating scars over the same period.

\section{DISCUSSION}

This is the first study, to our knowledge, that has compared scraping and excavating parrotfish grazing scars on coral colonies. Scraping and excavating graz- ing scars differed markedly in all analysed aspects, i.e. relative abundance across reef zones, scar depth, scar algal cover, structure of scar groups and scar longevity. These results reinforce the well-known differences between scraping and excavating parrotfishes on reef algae (e.g. Bellwood \& Choat 1990, Bruggemann et al. 1994b, Bonaldo \& Bellwood 2009) and brings an important complement to this scenario by showing that morphological and behavioural differences between these fish groups have additional implications in the way that they impact coral colonies in reef systems.

The positive relationship between the relative abundance of scraping and excavating parrotfishes and their respective grazing scars suggests that the composition of the parrotfish assemblage on coral reefs may be a good indicator of the relative contribution of scraping and excavating parrotfishes to coral predation. Parrotfish abundance has been previously correlated to coral predation pressure in the Caribbean (Rotjan \& Lewis 2006) and on the GBR (Bonaldo \& Bellwood 2011). Additionally, the composition of corallivorous communities on coral reefs can directly indicate the type and intensity of coral predation on a given reef. For example, reefs with corallivorous fish assemblages dominated by parrotfishes, such as the Caribbean (Rotjan \& Lewis 2006) and the GBR (Bonaldo \& Bellwood 2011), usually have a higher number of reef 
fish grazing scars per coral tissue area compared with reefs dominated by species with low feeding rates (e.g. monacanthids and tetradontids), such as in Hawaii (Jayewardene et al. 2009). Thus, the present study corroborates the results of previous studies that have reported relationships between the abundance of corallivorous fishes and coral predation pressure (e.g. Rotjan \& Lewis 2006, Bonaldo \& Bellwood 2011) and brings important complementary information by suggesting that the relative numbers of scraping and excavating parrotfishes in a location may indicate the dominant type of coral predation by parrotfishes in a system. However, further studies are necessary to verify this relationship, especially on the GBR, as the exact identity of the scraping and excavating parrotfish species inflicting the bite marks remains unknown.

In the present study, scraping and excavating grazing scars on massive Porites spp. differed markedly in the degree of coral exposed, as excavating grazing scars exposed more coral skeleton than scraping scars. The mean $( \pm \mathrm{SE})$ depth of grazing scars of large individuals of the scraping parrotfish Scarus rivulatus and the excavator Chlorurus microrhinos on dead coral surfaces covered by algal turfs is approximately $3.25 \pm$ 0.32 and $4.89 \pm 0.29 \mathrm{~mm}$, respectively (Bonaldo \& Bellwood 2009). S. rivulatus and C. microrhinos are also known to feed on live coral colonies (Bellwood \& Choat 1990, Bonaldo \& Bellwood 2011) and, thus, it is likely that the depth of their grazing scars on live coral colonies is similar to the values found on dead coral surfaces. Tissue layer thickness of massive Porites spp. usually ranges between 3.5 and $4.5 \mathrm{~mm}$ (Barnes \& Lough 1999, Carricart-Ganivet et al. 2007). As a consequence, grazing scars of $S$. rivulatus would be mostly limited to the living tissue of massive Porites spp., whereas bites of $C$. microrhinos could easily pass through this layer, reaching the underlying coral skeleton.

The differences in the depth of scraping and excavating grazing scars probably explains the higher algal cover and number of scars with algae in excavating scars compared with scraping scars. At least $50 \%$ of the area of excavating grazing scars exposed coral skeleton. In contrast, very few scraping grazing scars had any degree of coral skeleton exposure, and this corresponded to less than $1 \%$ of total scar area. Coral defence is predominantly undertaken by components exclusively found in coral living tissue (De Ruyter van Steveninck et al. 1988, McCook 2001, Jompa \& McCook 2002, Nugues et al. 2004). As a consequence, coral defence within excavating grazing scars is probably reduced, facilitating the settlement and development of algal spores. Additionally, excavating grazing scars last longer than scraping scars, providing more time for the development and growth of algae in the scars. Excavating grazing scars thus seem to represent more potential colonization sites for algal occupation on coral colonies compared with the shallow, shortlasting scraping grazing scars.

Differences in the depth of scraping and excavating grazing scars probably also explain the variation in the healing time of coral areas affected by these 2 types of parrotfish grazing scars. Scraping scars apparently just affect coral colonies superficially, removing only a thin living layer of coral tissue. Excavating grazing scars, however, remove all coral living parts, including polyps, and portions of the skeleton. As a consequence, regeneration of colony areas affected by excavating grazing scars probably requires higher allocation of energy and resources than a comparable area with scraping scars (Meesters et al. 1994). It would be expected that excavating grazing scars take longer to be repaired than scraping scars.

The differences in the impact of scraping and excavating parrotfishes on coral colonies are exacerbated for grouped scars. Groups of excavating grazing scars were always arranged as 'focused bites' (sensu Bruckner et al. 2000), characterized by the overlapping of bites and lack of coral tissue between bite marks. In contrast, scraping grazing scars were always grouped as 'spot bites', with scars well separated by gaps of coral tissue. Previous studies in the Western Atlantic showed that coral tissue regenerates rapidly over spot bites, but colonies affected by focused biting usually have a slower recovery (Bruckner \& Bruckner 1998, Bruckner et al. 2000). The overlapping grazing scars in the excavating groups result in an increase in the effective scar area and a decrease in the relative length of margins for regeneration. Colony areas with a high number of focused bites may experience partial coral mortality, with the surviving portions growing around the damaged area (Bruckner et al. 2000). Thus, although spot bites seem to have little impact on coral colonies, the focused feeding of excavating parrotfishes may have a more profound effect on the colonies and may even cause the mortality of colony areas, changing the colony's shape and complexity. This may be particularly important in the largest excavator, Bolbometopon muricatum, which removes approximately $15 \mathrm{~kg}$ of living coral per $\mathrm{m}^{2}$ in heavily grazed areas (Bellwood et al. 2003, Hoey \& Bellwood 2008).

The higher relative algal cover on grouped scars compared with individual scars suggests that this locally intense coral predation by parrotfishes may be an important factor in facilitating algal settlement and growth on coral colonies. Grouped scars produce larger and deeper wounds on coral surfaces, slowing the colony healing process. As a consequence, algae would have more time to settle, establish and grow on 
areas with groups of scars. This is particularly important in excavating grazing scars, as grouped scars prompt the opening of large areas completely free of coral tissue.

The absence of mixed groups of scraping and excavating parrotfish grazing scars at this study location is probably explained by the behaviour of the 2 parrotfish feeding groups. Excavating parrotfish species feed preferentially on convex surfaces whereas scrapers feed mostly on flat and concave surfaces (Bellwood \& Choat 1990, Bruggemann et al. 1994b). These differences may also explain the differential structure and density of groups of scraping and excavating grazing scars (spot biting scraping groups versus focused biting excavating groups). Excavating parrotfishes significantly modify the shape of the coral colony, opening holes in the coral surface and leaving some clear edges around the scar. As a consequence, the edges of the first excavating parrotfish bite provide a convex area between the coral and the grazing scar, facilitating coral predation by other excavating parrotfish individuals. In contrast, scraping grazers usually target flat or concave surfaces and, as a result, are unlikely to bite areas with pre-existing grazing scars.

A previous study found that the relative abundance and size of the massive Porites coral colonies on the reef flat and crest is smaller than those on the slope and backreef in the study area (Bonaldo \& Bellwood 2011). These authors also found a negative relationship between the abundance of massive Porites spp. and the abundance of parrotfish individuals. As a consequence, it has been suggested that parrotfish feeding may limit the development of preferred coral species, such as massive Porites spp., in areas where parrotfishes are more abundant (Bonaldo \& Bellwood 2011). In the present study, groups of grazing scars seem to have a more negative effect on coral colonies compared with individual grazing scars, and these groups were relatively more abundant in the reef crest and flat. The present findings, therefore, reinforce the previous suggestions that grazing scars of parrotfishes may negatively affect massive Porites colonies in some reef zones on the GBR.

Parrotfishes remain one of the few reef fish groups that are able to feed on and alter the structure of almost all coral reef benthic substratum types. A previous study on an inshore reef on the GBR found marked differences in the depth and regeneration time of scraping and excavating parrotfish grazing scars on dead coral surfaces covered by algal turfs (Bonaldo \& Bellwood 2009). The present study indicates that differences between scraping and excavating grazing scars may be even more significant on coral colonies than on algae. Grazing scars of the scraping parrotfish Scarus rivualtus and the excavator Chlorurus microrhi- nos on algal turfs disappear approximately 5 and $14 \mathrm{~d}$ following their appearance, respectively (Bonaldo \& Bellwood 2009). However, in the present study, although scraping grazing scars were completely regenerated after 2 mo, excavating scars displayed very little reduction during this period. As a consequence, it is likely that scraping and excavating parrotfish grazing scars may have marked differences in the way they impact the health and survivorship of coral colonies. These results emphasize the potential importance of parrotfish feeding in shaping benthic substratum composition and community dynamics on coral reefs

Although the vast majority of bites taken by parrotfishes are on algae (Bellwood \& Choat 1990, Bruggemann et al. 1994a, Bonaldo \& Bellwood 2008), recent studies on parrotfish feeding ecology have discussed the role of parrotfishes as coral consumers on tropical reefs (e.g. Littler et al. 1989, Hixon 1997, Rotjan \& Lewis 2005, Hoey \& Bellwood 2008, Mumby 2009). In this context, it has been found that parrotfishes may have a significant impact on coral colonies, as they can change the distribution and abundance of coral species selected for feeding (e.g. Littler et al. 1989, Hixon 1997, Rotjan \& Lewis 2005). The present study corroborates these findings, especially for excavating parrotfish, which leave grazing scars that are relatively deeper, longer-lasting and more frequently covered by algae. Excavating grazing scars, however, were rare in 3 of the 4 reef zones, and if these scars are responsible for coral mortality or decreased fitness at the study sites, this would be most evident in the backreef. In contrast, although scraping grazing scars were relatively shallower and shorter lasting, they were very abundant on the reef crest and flat, the 2 reef zones with the lowest cover of massive Porites spp. (Bonaldo \& Bellwood 2011). So, although scraping grazing scars may not appear to affect coral colonies through the opening of colonization sites for algae, they probably exert their greatest influence on corals though the energetic cost of damage, reflecting their high abundance in reef crest and flat habitats. However, this is currently just a correlation, not a demonstrable causation. Parrotfish grazing may affect coral mortality, but experimental evaluations are required to examine the extent of their impact. Although it does appear that parrotfishes will negatively affect Porites spp. growth and survival in different reef zones, other factors, such as hydrodynamics and depth, may also directly influence the distribution of coral colonies across the reef (Done 1982, De Vantier et al. 2006). Parrotfish corallivory thus appears to be another, but potentially significant, factor shaping distributions across reef gradients.

Continuous predation has been shown to be an energy drain for corals through the allocation of resources to tissue regeneration. Injured coral colonies 
usually have lower growth and calcification rates than intact colonies (Rotjan \& Lewis 2005, Meesters et al. 1994). Thus, scraping and excavating parrotfishes probably differentially affect the distribution and survivorship of coral colonies: although intense scraping parrotfish activity may reduce the growth rates of coral colonies, excavating feeding may promote the opening of deeper wounds on the colonies, facilitating the settlement of algae on the coral tissue.

Overall, the present study emphasizes the functional differences among the parrotfishes, a group well recognized for their importance in shaping the benthic structure of coral reefs (Bellwood et al. 2004, Paddack et al. 2006, Cole et al. 2008, Rotjan \& Lewis 2008, Bonaldo \& Bellwood 2009, Mumby 2009). Several individual parrotfish species and groups have been associated with crucial functional roles in reef systems, such as the control of algal communities (Paddack et al. 2006, Fox \& Bellwood 2007, Bonaldo \& Bellwood 2008, 2009, Burkepile \& Hay 2008), reef bioerosion (Bellwood et al. 2003, Alwany et al. 2009, Ong \& Holland 2010) and coral predation (Bruckner et al. 2000, Francini-Filho et al. 2008, Bonaldo \& Bellwood 2011). The present study complements this list by providing evidence to suggest that parrotfishes with different feeding modes may have important but significantly different impacts on coral colonies, especially massive Porites spp. on the GBR.

Acknowledgements. We thank R. J. Fox, C. H. Goatley and A. González-Cabello for assistance in the field; A. Baird, J. H. Choat and 3 anonymous reviewers for helpful comments and discussions; Lizard Island Research Station staff for logistical support. This work has been supported by a CAPES fellowship from the Brazilian Federal Government, a Lizard Island (Australian Museum) Doctoral Fellowship (R.M.B.) and the Australian Research Council Centre of Excellence for Coral Reef Studies.

\section{LITERATURE CITED}

Alwany MA, Thaler E, Stachowitsch M (2009) Parrotfish bioerosion on Egyptian Red Sea reefs. J Exp Mar Biol Ecol 371:170-176

Barnes DJ, Lough JM (1999) Porites growth characteristics in a changed environmet: Misima Island, Papua New Guinea. Coral Reefs 18:213-218

Bellwood DR (1994) A phylogenetic study of the parrotfishes family Scaridae (Pisces: Labroidei), with a revision of genera. Rec Aust Mus (Suppl 20):1-86

Bellwood DR, Choat DR (1990) A functional analysis of grazing in parrotfishes (family Scaridae): the ecological implications. Environ Biol Fishes 28:189-214

Bellwood DR, Hoey AS, Choat JH (2003) Limited functional redundancy in high diversity systems: resilience and ecosystem function on coral reefs. Ecol Lett 6:281-285

Bellwood DR, Hughes TP, Folke C, Nystrom M (2004) Confronting the coral reef crisis. Nature 429:827-833

Bonaldo RM, Bellwood DR (2008) Size-dependent variation in the functional role of the parrotfish Scarus rivulatus on the Great Barrier Reef, Australia. Mar Ecol Prog Ser 360: 237-244

> Bonaldo RM, Bellwood DR (2009) Dynamics of parrotfish grazing scars. Mar Biol 156:771-777

Bonaldo RM, Bellwood DR (2011) Parrotfish predation on massive Porites on the Great Barrier Reef. Coral Reefs (in press) doi:10.1007/s00338-010-0669-3

Bruckner AW, Bruckner RJ (1998) Destruction of coral by Sparisoma viride. Coral Reefs 17:350

> Bruckner AW, Bruckner RJ, Sollins P (2000) Parrotfish predation on live coral: 'spot biting' and 'focused biting'. Coral Reefs 19:50

> Bruggemann JH, Kuyper MWM, Breeman AM (1994a) Comparative analysis of foraging and habitat use by the sympatric Caribbean parrotfish Scarus vetula and Sparisoma viride. Mar Ecol Prog Ser 112:51-66

> Bruggemann JH, van Oppen MJH, Breeman AM (1994b) Foraging by the stoplight parrotfish Sparisoma viride. I. Food selection in different, socially determined habitats. Mar Ecol Prog Ser 106:41-55

Burkepile DE, Hay ME (2008) Herbivore species richness and feeding complementarity affect community structure and function on a coral reef. Proc Natl Acad Sci USA 105: 16201-16206

Carricart-Ganivet JP, Lough JM, Barnes DJ (2007) Growth and luminescence characteristics in skeletons of massive Porites from a depth gradient in the central Great Barrier Reef. J Exp Mar Biol Ecol 351:27-36

Cole AJ, Pratchett MS, Jones GP (2008) Diversity and functional importance of coral-feeding fishes on tropical coral reefs. Fish Fish 9:286-307

De Ruyter van Steveninck ED, van Mulekom LL, Breeman AM (1988) Growth inhibition of Lobophora variegata (Lamouroux) Womersley by scleractinian corals. J Exp Mar Biol Ecol 115:169-178

> DeVantier LM, De'ath G, Turak E, Done TJ, Fabricius K (2006) Species richness and community structure of reefbuilding corals on the nearshore Great Barrier Reef. Coral Reefs 25:329-340

> Done TJ (1982) Patterns in the distribution of coral communities across the central Great Barrier Reef. Coral Reefs 1:95-107

Fox RJ, Bellwood DR (2007) Quantifying herbivory across a coral reef depth gradient. Mar Ecol Prog Ser 339:49-59

> Francini-Filho RB, Moura RL, Ferreira CM, Coni EOC (2008) Live coral predation by parrotfishes (Perciformes: Scaridae) in the Abrolhos Bank, eastern Brazil, with comments on the classification of species into functional groups. Neotrop Ichthyol 6:191-200

Hixon MA (1997) Effects of reef fishes on corals and algae. In: Birkeland C (ed) Life and death of coral reefs. Chapman \& Hall, New York, NY, p 230-248

Hoey AS, Bellwood DR (2008) Cross shelf variation in the role of parrotfishes on the Great Barrier Reef. Coral Reefs 27: $37-47$

> Hughes TP, Rodrigues MJ, Bellwood DR, Ceccarelli D and others (2007) Phase shifts, herbivory, and the resilience of coral reefs to climate change. Curr Biol 17:360-365

Jayewardene D, Birkeland C (2006) Fish predation on Hawaiian corals. Coral Reefs 25:328

Jayewardene D, Donahue MJ, Birkeland C (2009) Effects of frequent fish predation on corals in Hawaii. Coral Reefs 28:499-506

Jompa J, McCook LJ (2002) Effects of competition and herbivory on interactions between a hard coral and a brown alga. J Exp Mar Biol Ecol 271:25-39 
Littler MM, Taylor PR, Littler DS (1989) Complex interactions in the control of coral zonation on a Caribbean reef flat. Oecologia 80:331-340

McCook LJ (2001) Competition between corals and algal turfs along a gradient of terrestrial influence in the nearshore central Great Barrier Reef. Coral Reefs 19:419-425

Meesters EH, Noordeloos M, Bak RPM (1994) Damage and regeneration: links to growth in the reef-building coral Montastrea annularis. Mar Ecol Prog Ser 112:119-128

Mumby PJ (2009) Herbivory versus corallivory: Are parrotfish good or bad for Caribbean coral reefs? Coral Reefs 28:683-690

Mumby PJ, Dahlgren CP, Harborne AR, Kappel CV and others (2006) Fishing, trophic cascades and the process of grazing on coral reefs. Science 311:98-101

Nugues MM, Delvoye L, Bak RPM (2004) Coral defense against macroalgae: differential effects of mesenterial filaments on the green algae Hamelida opuntia. Mar Ecol

Editorial responsibility: Charles Birkeland,

Honolulu, Hawaii, USA
Prog Ser 278:103-114

Ong L, Holland KN (2010) Bioerosion of coral reefs by two Hawaiian parrotfishes: species, size differences and fishery implications. Mar Biol 157:1313-1323

> Paddack MJ, Cowen RK, Sponaugle S (2006) Grazing pressure of herbivorous coral reef fishes on low coral-cover reefs. Coral Reefs 25:461-472

Rotjan RD, Lewis SM (2005) Selective predation by parrotfishes on the reef coral Porites astreoides. Mar Ecol Prog Ser 305:193-201

Rotjan RD, Lewis SM (2006) Parrotfish abundance and selective corallivory on a Belizean coral reef. J Exp Mar Biol Ecol 335:292-301

Rotjan RD, Lewis SM (2008) Impact of coral predators on tropical reefs. Mar Ecol Prog Ser 367:73-91

Sánchez JA, Gil MF, Chasqui LH, Alvarado EM (2004) Grazing dynamics on a Caribbean reef-building coral. Coral Reefs 23:578-583

Submitted: August 13, 2010; Accepted: November 21, 2010

Proofs received from author(s): January 27, 2011 